\title{
The effect of self-rated health, subjective socioeconomic status, social capital, and physical activity on life satisfaction: a cross- sectional study in urban western Iran
}

\author{
Nader Rajabi Gilan', Mehdi khezeli ${ }^{1}$ and Shirin Zardoshtian ${ }^{2 *}$
}

\begin{abstract}
Background: Life satisfaction is an important component in designing strategies to improve health outcomes in different groups of society. This study aimed to investigate the effect of subjective socioeconomic status (SSS), social capital (SC), self-rated health (SRH), and physical activity (PA) on life satisfaction (LS) in Iran.

Methods: This cross-sectional study was conducted on 1187 people (643 men and 544 women) lived in five western cities in Iran. The sampling method was multistage clustering. Data collection tool was a five part questionnaire including demographic characteristics, socioeconomic status ladder, social capital scale, a question to measure physical activity, and the life satisfaction scale. Data were analyzed using independent t-test, one way ANOVA, and Ordinal Logistic Regression.

Result: Life satisfaction was higher in married men and women compared to single and widows $(p<0.05)$. Among the variables included in the main model, the significant predictors were college education $(-0.500)$, marriage (coefficient $=0.422$ ), age $25-34$ years (coefficient $=-0.384)$, SRH (coefficient $=0.477)$, male sex (coefficient $=0.425)$, SSS (coefficient $=0.373$ ), trust (coefficient $=0.115)$, and belonging and empathy (coefficient $=0.064$ ).

Conclusion: SRH and SSS were significant predictors of life satisfaction in west Iranian society. Being married was associated with higher LS, but college education affects LS adversely.
\end{abstract}

Keywords: Life satisfaction, Self-rated health, Socioeconomic status, Social trust, Well-being

\section{Background}

Well-being assessment is one of the main priorities for governments, international organizations, health companies and research institutions [1]. Life satisfaction (LS) as a main component of subjective well-being is routinely used as an only measurement of subjective wellbeing in many studies [2,3]. LS is a universal assessment of one's life based on one's subjective criteria. it includes

\footnotetext{
* Correspondence: sh.zardoshtian@razi.ac.ir

${ }^{2}$ Department of Sport Management, Faculty of Sport Science, Razi University, Kermanshah, Iran

Full list of author information is available at the end of the article
}

an individual's self-assessment about life's adaptation according to the internal expectations [4]. The study of LS given that it depends on individuals and social context can be examined at different times and various demographic groups [5]. Researchers have shown that people with high level of LS compared to those with lower level tend to have more positive social relationships, marital satisfaction, and experience social support [6]. In the present study according to the previous studies and literature, we examined the association between some demographic, physical and social factors with LS. Some studies emphasized that four factors directly influences

(c) The Author(s). 2021 Open Access This article is licensed under a Creative Commons Attribution 4.0 International License, which permits use, sharing, adaptation, distribution and reproduction in any medium or format, as long as you give appropriate credit to the original author(s) and the source, provide a link to the Creative Commons licence, and indicate if changes were made. The images or other third party material in this article are included in the article's Creative Commons licence, unless indicated otherwise in a credit line to the material. If material is not included in the article's Creative Commons licence and your intended use is not permitted by statutory regulation or exceeds the permitted use, you will need to obtain permission directly from the copyright holder. To view a copy of this licence, visit http://creativecommons.org/licenses/by/4.0/. The Creative Commons Public Domain Dedication waiver (http://creativecommons.org/publicdomain/zero/1.0/) applies to the data made available in this article, unless otherwise stated in a credit line to the data. 
the level of LS including physical health condition, mental health condition, social relationship and environment [7].Self-rated health (SRH) represents a meaningful, subjective indicator for health status. It is an interested new assessment based on the individual appraisal of one's health that includes an overall sense of functioning, physical, mental and social dimensions of health [8]. The self-rated health index has been widely used in recent years in studies and the results have shown that it is associated with life satisfaction [9-11].

Physical activity is another variable related to wellbeing and life satisfaction which refers any movement in daily life and has three levels of work, sport and leisure [12]. Worldwide, physical inactivity is one of the leading causes of disease, disability, and preventable death, while PA is an important protective factor against the development of chronic diseases [13]. Although a mass body of studies and evidence show that physical activity is directly related to various aspects of health $[14,15]$, there is less evidence to link physical activity to life satisfaction and mental well-being based on community-based studies. In this regard, some studies in different groups confirm the positive relationship between PA and LS, and mental well-being [16-18], instead, some studies have reported a lack of significant relationship or contradictory results $[19,20]$.

One of the most important limitations of some studies in the field of LS is ignoring social relationships and factors [21]. Social capital (SC) is one of the main social factors in sociology, health promotion, and health economic literature [22]. SC defined by Putnam and determined by variables such as social trust, cross-trade norms, and social network density [23]. Results from a study in China indicated that social capital had the significant positive effect on LS, according to which the social capital improves the life satisfaction through promoting positive affect [24]. Another study with community based approach in Rotterdam, Netherlands showed the significant positive association between neighborhood-based social capital and individual LS [25].

There are several definitions and measures for recognizing social capital, introduced by Asadullah et al. (2017), in which the average response to the trust question are acknowledge as the standard measure for social capital [26]. One of the approaches to the social capital is to divide it into bonding and bridging types [27]. Bonding social capital refers to robust social ties based on family relationships, kinship, gender, ethnicity, and religion. Bridging social capital is also based on the relationships of individuals and groups with dissimilar others [28]. Social capital in traditional societies almost includes bonding aspect with specific social trust, and in modern societies is mostly a bridging aspect with generalized social trust [28]. Also, the cultural context of Iran, especially in the western provinces where this research has been conducted is socially unbalanced that create a mixture of traditional and modern social capital.

Socioeconomic status (SES) is another important social variable affecting subjective well-being examined in this study. SES is one of the strongest predictors of individual diseases and mortality [29], that is why research on the role of socioeconomic factors on health and disease has been increasing worldwide in recent years [30]. Based on the evidence and studies, Huang et al. have defined two main types of socioeconomic status. Objective SES is the economic and social position about others, which is widely measured using three indicators: income, education, and occupation. In contrast, subjective SES is a person's conception of his or her position compared with that of others [31]. There are many qualitative and quantitative studies show that high levels of socioeconomic status are associated with higher levels of life satisfaction in different social groups [32-34].

Despite the importance of social factors and PA on life satisfaction, we did not find a study in Iran on this issue in the general population. Therefore, this study aimed to investigate the relationship between SRH, SC, SSS, and PA with LS in five western provinces of Iran. Main research hypothesis of this study was that socioeconomic status, social capital and physical activity are related to and predict the life satisfaction in general population of urban western Iran.

\section{Method}

\section{Study design and participants}

This was a cross-sectional study. The target population of the study was the population aged above 16 years nearly 2 million people in five province centers located at west of Iran include Kermanshah, Sanandaj, Ilam, Hamadan, and Khorramabad. Sample size was calculated using the results of the similar previous studies, according to which the final sample size was 1268 . The proportion of each city (Kermanshah 483 people, Hamadan 283, Sanandaj 215, Khorramabad 187 and Ilam 100) was calculated according to the each urban population and cluster sampling method was used to select the samples. For this purpose, each municipality district was considered as a cluster in each city. The number of municipality districts or clusters included: Kermanshah eight districts, Hamadan four districts, Sanandaj three districts, Khorramabad three districts, and two districts. Then, two neighborhoods were randomly assigned from each cluster. Finally, according to the population of the neighborhoods, samples were selected in each neighborhood using convenience sampling method. Inclusion criteria were consent to participate in the study, lack of physical disability and acute mental illness, and age over 16 years. In the present study, 1268 individual received 
the study questionnaire and finally 1187 participants completed the questionnaire which showed the response rate of $93.5 \%$.

\section{Measurements}

Data collection tool was a five part questionnaire. The first section was questions on demographic information including age, sex (1- male; 2 - female), marital status (1single; 2- married; 3- widow), and education levels (1under diploma; 2- diploma; 3- college). PA in second part was assessed with one question as "how many days a week have you had at least 30 minutes of moderate to vigorous physical activity such as walking, swimming, fitness, mountaineering, etc.? " on a four point scale (1never; 2 - one to three time a month; 3- one to two times a week; 4- three and above times a week) [35]. The third part of questionnaire was a SSS scale which assesses current SSS using a social ladder [36, 37]. The subjective evaluation of SES is the self-conceiving of the individual's position in the social structure. This scale assesses perception of individuals about job, education, and wealth dimensions on a 10-point ladder, in which the higher score indicated the better perception about SSS.

The fourth part was the Satisfaction with Life Scale (SWLS) developed by Diener et al. (1985) [4]. This scale consists of five-items including: 1) In most ways my life is close to my ideal, 2) The conditions of my life are excellent, 3) I am satisfied with my life, 4) So far I have gotten the important things I want in life, 5) If I could live my life over, I would change almost nothing. Each item rates on a five-point Likert scale $(1=$ strongly disagree to $5=$ strongly agree), and total score of scale can be ranged from 5 to 25 , according to which higher scores indicates greater LS. According to the previous studies we divided scores into 5 categories from very dissatisfied to very satisfied [10]. Then due to the small number of respondents who assessed their LS as very dissatisfied and very satisfied, these two categories are combined in the dissatisfied and satisfied categories, and finally we had three categories including: very dissatisfied or dissatisfied / so-so / satisfied or very satisfied. Finally 3-point scale for each item was recorded, with the total scale range from 5 to 15 . This tool has been validated in an Iranian research by Vahedi and Eskandari (2010) with an acceptable reliability using Cronbach's alpha. Concurrent validity of the Life Satisfaction Scale was assessed through correlation with WHO Quality of Life Questionnaire, according to which there were significant correlations with the four subscales of QOL questionnaire including mental health, physical health, social relationships, and environmental health [38].

The fifth part of the questionnaire assessed the selfrated health using a single question; "How is your health in general?" extracted from the World Health
Organization Quality of Life Questionnaire (WHOQOLBREF). This question measures the SRH on a 5-point Likert scale (very bad / bad / not good not bad / good / very good). The higher score shows the better SRH [39].

The final part of the questionnaire was Social Capital scale introduced by Rafiey et al., (2019) consists of 20 items on five point Likert scale that measure two forms of bonding and bridging SC. The total score of scale in continuous measuring can be ranged between 20 and 100 score in which higher score indicated the higher level of SC (Table 1). In the present study we used the bonding social capital subscale consisted of three factors including empathy and belonging (six question), trust (three question), and partnership (two question) [28]. The reliability of the questionnaire was confirmed with Cronbach's alpha coefficient of 0.92 .

\section{Ethical statement}

This study received the ethics approval from the Research Ethics Committee of Kermanshah University of Medical Sciences (No.IR.KUMS.REC.1398.118). Written informed consent form was obtained from all of the participants.

\section{Data collection and statistical analysis}

Data were collected from October to November 2019 by trained and informed interviewers about the environment and social context of each district. Data were analyzed by Statistical Package for the Social Sciences (SPSS-18) and STATA-8. Since, our dependent variable (LS) was an ordinal variable; hence the appropriate technique for the analysis was Ordinal Logistic Regression Method [10, 40]. Also we used independent t-test, and one way ANOVA to compare the mean of LS in different groups. Mean and standard deviation was used to report the descriptive status of variables. A 95\% level of confidence was assumed.

\section{Results}

In the present study, mean age of the participants was $33.12 \pm 12.61$ years. More than half of the participants were male $(54.2 \%)$; had college education $(51.3 \%)$, and were single $(50.6 \%)$. Also the highest frequency in age groups was in $25-34$ years with $33.2 \%$.

Results also showed that 330 (27.8\%) participants reported that they were very dissatisfied or dissatisfied with life, 464 (39.1\%) neither dissatisfied nor satisfied, and 393 (33.1\%) were satisfied or very satisfied with life. As shown in Table 2, the mean score of life satisfaction in women was higher than men ( $p$-value $<0.001)$. Mean score of LS also was different among SRH groups $(p$ value $<0.001)$, and SSS categories ( $p$-value $<0.001)$. Results provided in Table 3 showed that the life satisfaction was significantly higher in married (both genders) than 


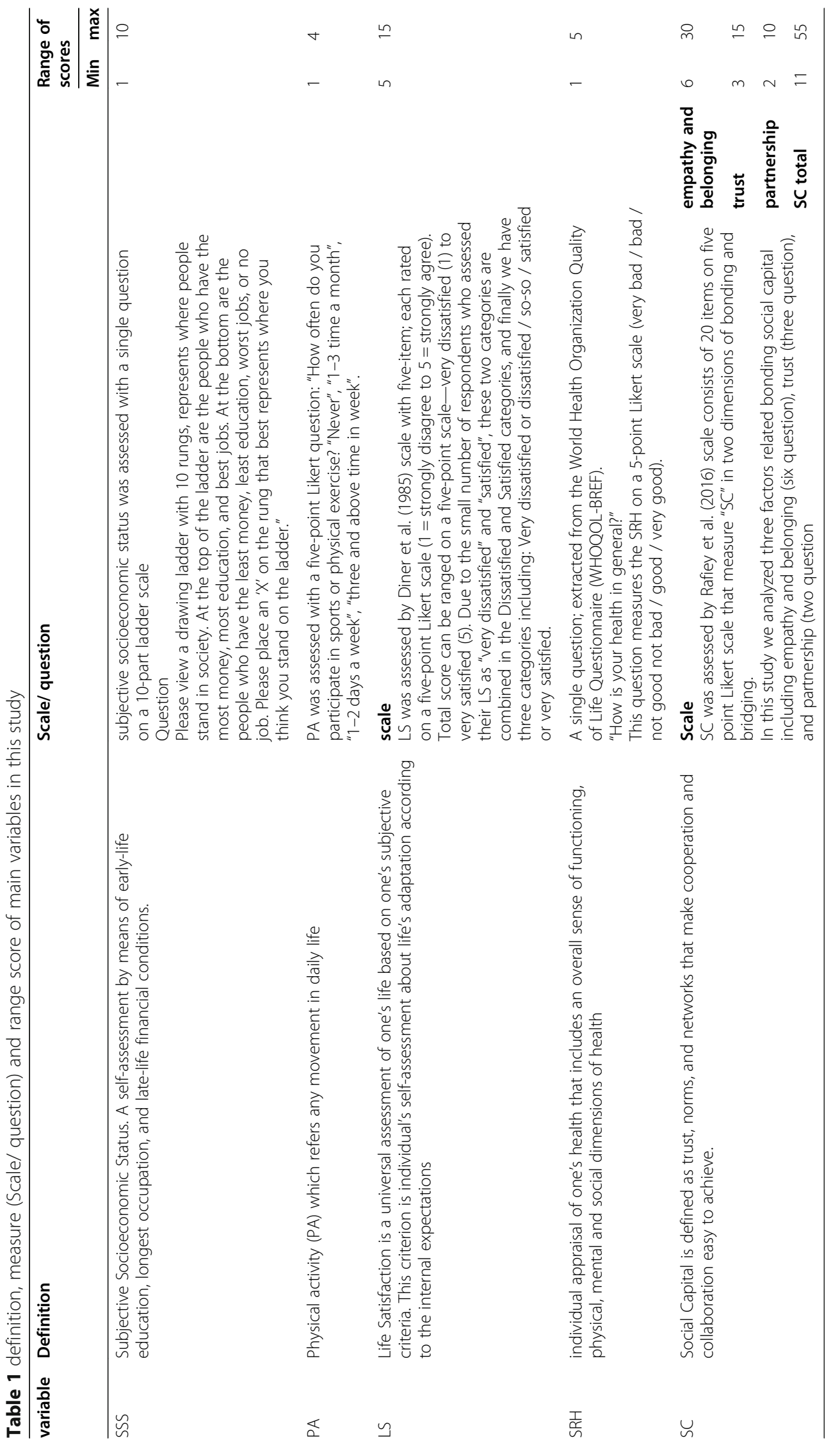


Table 2 mean (SD) of LS according to the independent variables $(n=1187)$

\begin{tabular}{|c|c|c|c|c|c|}
\hline \multirow{2}{*}{$\begin{array}{l}\text { Independent } \\
\text { variables }\end{array}$} & \multirow[t]{2}{*}{ Category } & \multirow[t]{2}{*}{ N [\%] } & \multicolumn{2}{|c|}{ Life satisfaction (LS) } & \multirow[t]{2}{*}{$P$-value } \\
\hline & & & Mean & (SD) & \\
\hline \multirow[t]{2}{*}{ Sex } & Male & $643[54.2]$ & 8.83 & $(2.88)$ & 0.001 \\
\hline & Female & $544[45.8]$ & 9.43 & (3.29) & \\
\hline \multirow[t]{6}{*}{ Age group } & 16-24 year & $360[30.3]$ & 9.10 & $(2.95)$ & 0.151 \\
\hline & 25-34 year & $394[33.2]$ & 8.90 & (3.15) & \\
\hline & 35-44 year & $220[18.5]$ & 9.10 & $(2.89)$ & \\
\hline & 45-54 year & 118[9.9] & 9.33 & (3.14) & \\
\hline & 55-64 year & $69[5.8]$ & 9.60 & $(3.71)$ & \\
\hline & $65-75$ year & $26[2.2]$ & 10.30 & (3.44) & \\
\hline \multirow[t]{3}{*}{ Marriage } & single & $601[50.6]$ & 8.72 & $(2.92)$ & 0.001 \\
\hline & Married & $542[45.7]$ & 9.62 & $(3.17)$ & \\
\hline & Widow and divorced & $44[3.7]$ & 8.06 & (3.32) & \\
\hline \multirow[t]{3}{*}{ Education } & Under diploma & $190[16.0]$ & 9.12 & $(3.27)$ & 0.629 \\
\hline & diploma & $388[32.7]$ & 8.99 & (3.02) & \\
\hline & College & $609[51.3]$ & 9.18 & (3.08) & \\
\hline \multirow[t]{4}{*}{ physical activity (PA) } & Never & $276[23.3]$ & 8.21 & $(3.00)$ & 0.001 \\
\hline & 1-3 times a month & $316[26.7]$ & 8.85 & $(2.99)$ & \\
\hline & 1-2 times a week & $364[30.7]$ & 9.74 & (3.15) & \\
\hline & 3 or more times a week & $231[19.5]$ & 9.54 & $(2.94)$ & \\
\hline \multirow[t]{5}{*}{ SRH } & Very bad & $59[5.0]$ & 7.54 & (3.35) & 0.001 \\
\hline & Bad & $87[7.3]$ & 7.25 & $(2.89)$ & \\
\hline & Not bad - not good & 318 [26.8] & 8.14 & $(2.82)$ & \\
\hline & Good & $547[46.1]$ & 9.61 & $(2.92)$ & \\
\hline & Very good & $176[14.6]$ & 10.67 & $(2.85)$ & \\
\hline \multirow[t]{11}{*}{ SSS } & 1 & $81[6.8]$ & 6.61 & $(2.22)$ & 0.001 \\
\hline & 2 & $99[8.3]$ & 7.47 & $(2.98)$ & \\
\hline & 3 & $148[12.5]$ & 7.79 & $(2.80)$ & \\
\hline & 4 & $152[12.7]$ & 8.18 & $(2.52)$ & \\
\hline & 5 & $275[23.1]$ & 9.21 & $(2.65)$ & \\
\hline & 6 & 152 [12.8] & 9.43 & $(2.83)$ & \\
\hline & 7 & $130[11.0]$ & 10.50 & $(2.63)$ & \\
\hline & 8 & $93[7.8]$ & 11.46 & $(2.85)$ & \\
\hline & 9 & $30[2.5]$ & 13.73 & $(1.52)$ & \\
\hline & 10 & $27[2.3]$ & 12.22 & $(2.96)$ & \\
\hline & Total participants & $1187[100]$ & 9.11 & $(3.05)$ & \\
\hline
\end{tabular}

Table 3 Comparison of average life satisfaction score by gender

\begin{tabular}{|c|c|c|c|c|c|c|}
\hline \multirow[t]{2}{*}{ Gender } & \multicolumn{3}{|c|}{ Mean (SD) of LS } & \multirow[t]{2}{*}{$F$} & \multirow[t]{2}{*}{$P$-value } & \multirow[t]{2}{*}{ Tukey test } \\
\hline & Single & Married & Widow & & & \\
\hline Male & $8.44(2.81)$ & $9.39(2.88)$ & $5.80(1.78)$ & 11.57 & 0.001 & Married $>$ Single, widow \\
\hline Female & $9.14(3.04)$ & $9.87(3.44)$ & $8.35(3.38)$ & 5.42 & 0.005 & Married $>$ Single, widow \\
\hline Total & $8.72(2.92)$ & $9.62(3.17)$ & $8.06(3.32)$ & 14.94 & 0.001 & Married $>$ Single, widow \\
\hline
\end{tabular}


single and widows, while singles and widows were not significantly different.

Ordinal Logistic Regression was used to determine the factors affecting life satisfaction. We had two analysis models: one without SRH (model 1), and another includes SRH (model 2). Estimates were slightly different in the two models: in model 1, physical activity 1 to 2 times a week was significant, but model 2 showed that the role of physical activity was not significant.Table 4 shows the main determinants of life satisfaction in two model according to the Ordinal Logistic Regression.
Results of model 2 showed that college education ($0.500, p$-value $=0.008)$ was a significant predictor to lower LS compared to under diploma education, while diploma and under diploma education were no different. Married condition (coefficient $=0.422, p$-value $=0.008$ ) was significant predictor compared to single and widowed. Another predictors were male (coefficient = $0.425, p$-value $=0.005)$, age of $25-34$ years compared to lower age (coefficient $=-0.0384, p$-value $=0.008)$, SRH (coefficient $=0.477, p$-value $<0.001$ ), and SSS (coefficient $=0.373, p$-value $<0.001)$. Among three dimension

Table 4 results of Ordinal Logistic Regression for determinants of LS ( $n=1187$ )

\begin{tabular}{|c|c|c|c|c|c|c|c|}
\hline \multirow[t]{2}{*}{ Variables } & \multirow[t]{2}{*}{ Categories } & \multicolumn{3}{|c|}{ Model 1} & \multicolumn{3}{|c|}{ Model 2} \\
\hline & & $\overline{\operatorname{Coef}(\beta)}$ & SE & $\overline{p \text {-value }}$ & $\operatorname{Coef}(\beta)$ & SE & $p$-value \\
\hline \multirow[t]{3}{*}{ Education } & Under diploma & Ref & & & Ref & & \\
\hline & diploma & -0.025 & 0.193 & 0.893 & -0.041 & 0.195 & 0.830 \\
\hline & College & -0.408 & 0.186 & 0.028 & -0.500 & 0.189 & 0.008 \\
\hline \multirow[t]{3}{*}{ Marital status } & Single & Ref & & & Ref & & \\
\hline & Married & 0.383 & 0.156 & 0.015 & 0.422 & 0.158 & 0.008 \\
\hline & Widow & 0.025 & 0.358 & 0.944 & 0.170 & 0.363 & 0.639 \\
\hline \multirow[t]{2}{*}{ Sex } & Female & Ref & & & Ref & & \\
\hline & Male & 0.368 & 0.128 & 0.004 & 0.425 & 0.129 & 0.001 \\
\hline \multirow[t]{6}{*}{ Age group } & $16-24$ years & Ref & & & Ref & & \\
\hline & $25-34$ years & -0.413 & 0.171 & 0.016 & -0.384 & 0.172 & 0.025 \\
\hline & $35-44$ years & -0.267 & 0.215 & 0.208 & -0.135 & 0.215 & 0.529 \\
\hline & 45-54 years & -0.376 & 0.261 & 0.150 & -0.242 & 0.265 & 0.361 \\
\hline & 55-64 years & -0.140 & 0.319 & 0.660 & 0.012 & 0.321 & 0.970 \\
\hline & $65-75$ years & 0.592 & 0.481 & 0.218 & 0.801 & 0.493 & 0.104 \\
\hline \multirow[t]{5}{*}{ Residence } & Sanandaj & Ref & & & Ref & & \\
\hline & Hamadan & -0.095 & 0.202 & 0.635 & -0.213 & 0.206 & 0.300 \\
\hline & Ilam & 0.547 & 0.266 & 0.040 & 0.448 & 0.267 & 0.094 \\
\hline & Khorram Abad & 0.330 & 0.222 & 0.136 & 0.307 & 0.224 & 0.171 \\
\hline & Kermanshah & -0.128 & 0.182 & 0.482 & -0.322 & 0.187 & 0.086 \\
\hline \multirow[t]{4}{*}{ physical activity } & never & Ref & & & Ref & & \\
\hline & 1-3 times a month & 0.179 & 0.177 & 0.312 & 0.088 & 0.179 & 0.620 \\
\hline & 1-2 times a week & 0.359 & 0.175 & 0.040 & 0.235 & 0.177 & 0.185 \\
\hline & three and above days in week & 0.196 & 0.197 & 0.320 & -0.013 & 0.201 & 0.945 \\
\hline \multicolumn{2}{|c|}{ Belonging and Empathy } & 0.075 & 0.015 & 0.001 & 0.064 & 0.015 & 0.001 \\
\hline \multicolumn{2}{|l|}{ Trust } & 0.123 & 0.026 & 0.001 & 0.115 & 0.026 & 0.001 \\
\hline \multicolumn{2}{|l|}{ partnership } & 0.091 & 0.037 & 0.016 & 0.060 & 0.038 & 0.115 \\
\hline \multicolumn{2}{|l|}{ SSS } & 0.411 & 0.033 & 0.001 & 0.373 & 0.033 & 0.001 \\
\hline \multicolumn{2}{|l|}{ SRH } & - & - & - & 0.477 & 0.076 & 0.001 \\
\hline \multicolumn{2}{|l|}{ Log likelihood } & \multicolumn{3}{|c|}{-964.14} & \multicolumn{3}{|l|}{-944.38} \\
\hline \multicolumn{2}{|l|}{ LR chi2 } & \multicolumn{3}{|c|}{ (21) 447.63} & \multicolumn{3}{|c|}{ (22) 487.41} \\
\hline \multicolumn{2}{|l|}{ Prob > chi2 } & \multicolumn{3}{|l|}{0.001} & \multicolumn{3}{|l|}{0.001} \\
\hline \multicolumn{2}{|l|}{ Pseudo R2 } & \multicolumn{3}{|l|}{0.1885} & \multicolumn{3}{|l|}{0.2051} \\
\hline \multicolumn{2}{|l|}{ Number of obs } & 1171 & & & 1171 & & \\
\hline
\end{tabular}


of bonding SC, trust (coefficient $=0.115, p$-value < 0.001 ), and belonging and empathy (coefficient $=0.064$, $p$-value $<0.001)$ were significant while partnership was not significant. Residence and physical activity were not significant.

\section{Discussion}

This study investigated the associations between SSS, $\mathrm{SRH}$, bonding SC, and PA with LS in urban population of western Iran.

The results of this study showed that SSS have a significant effect on life satisfaction. $\mathrm{Ng}$ and colleagues also showed that better perceived condition had a positive and significant effect on LS [10]. The results of a study in China showed that subjective well-being was affected by socioeconomic status, and the most influential variables in this regard were education, employment and income [41]. A study in Russia and Ukraine by Abbott \& Sapsford (2006) showed that human capital, financial conditions (economic status and ability to provide the necessities), income satisfaction, and family facilities had direct relationships with LS [42]. Also a study by Asadullah and a Chaudhury (2012) in Bangladesh showed that higher objective income and economic condition is related with the higher level of life satisfaction [43]. Here we can refer to Easterlin's theory of income and subjective well-being. Easterlin believes that increasing personal income can be a source of LS and happiness which confirms the results of the present study. However, the second part of Easterlin's theory, which is considered as a theoretical paradox and has shown that the economic growth of society does not cause happiness and mental well-being, has not been studied in this study [44]. It seems that when people compare their income and economic situation with others and are placed in a lower situation, are likely to experience pessimism and hopelessness [45]. This can reduce satisfaction from health, occupation, and income, and subsequently can lead to reduced LS and happiness. If one's assessment of living conditions be negative, this can influences and evolves many of the behaviors and attitudes toward the individual's situation and social circumstances [46].

Other result of this study showed a positive and significant relationship between bonding SC and LS. This finding was consistent with study by Ghasemi et al. (2017) on the relationship of social capital with LS in Iran [47]. Woo (2017) in a study in South Korea and Taiwan showed that social capital was positively correlated with LS in the Taiwanese sample by controlling variables such as subjective social status, self-rated health, gender, and individualism tendency while there was no significant relationship between SC and LS in the South Korean sample. The South Korean case revealed that social capital is not a good predictor for LS in an environment where success is over-emphasized [48].

Regression analysis showed that among bonding SC dimension, belonging and empathy, and trust had the direct and meaningful effects on LS. Mironova (2015) assessed the relationship between different types of trust (institutional, public, and social) with LS, according to which structural equation model showed that social trust had the most direct effect on LS [49], consistent with the present study. Trust is the heart of social and political stability in society and is important for the health and interpersonal relationships, so that the decline of trust in any society is a major constraint on social economic development [49]. Trust is a major factor in social well-being and one of the most important indicators of social well-being, and assessment of individuals' mental life satisfaction.

The results of the present study indicated the positive and significant effect of SRH on LS. Results of a study in Europe indicated that there was a positive association between self-reported health status and LS across countries [50]. In another study SRH was negatively associated to depressed mood, mediated by life satisfaction. An interactions showed that better economic situation compensated the effect of a low SRH on life satisfaction [51]. Schneider et al. also pointed out in another direction that life satisfaction is related to self-evaluation of health in the elderly [52]. However, the literature shows that there is a positive relationship between SRH and LS, and the present study concluded that higher SRH scores predict higher LS.

Other result of this study showed that college education level had a negative and decreasing effect on LS. This finding is inconsistent with the results of Jiménez's (2011) [53] and Martikainen (2010) [54]. However, results of a study in Europe showed that one level increase in education degree leads to an average of 0.03 decline in LS scores [55]. It seems that the negative impact of higher education on the LS in the present study is due to the high unemployment rate of university graduates in Iranian society [56]. As noted by Martikainen (2010), job satisfaction is a main influencing factors on life satisfaction [54]. It can also be said that people with higher education experience more stress and strain, which can reduce their life satisfaction.

The results showed that LS scores were significantly higher among married people than single and widows. Marriage in the regression model had a positive and significant effect on LS which was consistent with similar studies [57, 58]. Although the mean score of LS in women was higher than men, but more detailed results revealed that LS score in male and female married was not different and significantly was higher than singles and widows. Also, singles and widows in both sexes had 
no different LS score. It seems that regardless of being male or female, marriage is an appropriate emotional shield to promote mental health and well-being in individuals. Marriage provides various consequences and incentives such as lower mortality risk, shared household goods, and other benefits [59]. Stutzer \& Frey (2006) argue that marriage and individual well-being are positively correlated, because marriage is an additional source of self-esteem and married people are less likely to experience loneliness and have the opportunity to benefit from a supportive relationship [60].

Self-reporting was one of the limitation of this study which can increase the likelihood of over or under reporting. Another limitation of this study was using the subjective SES scale to assess the socioeconomic situation and not to examine the participants' objective income and its relationship with LS. An accurate assessment of income level in cross-sectional studies in Iran is difficult due to the lack of transparency, and the respondents' refusal to report their actual income. It should be noted that the perception of existing income is one of the aspects of subjective SES ladder that has been studied in this study. However, the present study was conducted with an appropriate sample size in urban area of five western provinces of Iran, which can provide a proper assessment of the life satisfaction of women in the urban population of western Iran.

\section{Conclusion}

This study showed that better SSS and being married had an increasing effect on LS in Iranian society. Belonging and empathy, and trust as emotional and cognitive dimensions of SC also increased the LS. It seems that social policies that create trust at the micro and macro level, and providing proper mechanisms for marriage in appropriate age groups can be useful in improving LS with considering the cultural and social contexts of western Iran.

\section{Abbreviations}

PA: Physical Activity; LS: Life Satisfaction; SC: Social Capital; SRH: Self-rated Health; SES: Socioeconomic Status; SSS: Subjective Socioeconomic Status

\section{Acknowledgments}

The researchers would like to thank all the participants.

\section{Authors' contributions}

NR designed the study in collaboration with ShZ. MKh performed recruitment and data collection. NR made the statistical analyses in collaboration with MKh. NR is the primary author in the writing of the manuscript. All authors critically revised and substantially contributed throughout the writing the manuscript. All authors read and approved the final manuscript.

\section{Funding}

This work is financially supported by the supported by Kermanshah University of Medical Sciences (Grant No. 980207). The funders played no role in the study design, data collection, data analysis, interpretation or writing of the report.

\section{Availability of data and materials}

The data sets used and analyzed in this study are available from the corresponding author on reasonable request.

\section{Ethics approval and consent to participate}

This study received ethics approval from the Research Ethics Committee of Kermanshah University of Medical Sciences (No.IR.KUMS.REC.1398.118). Written informed consent form was obtained from the participants and in cases under 16 years, written consent was obtained from their parents.

Consent for publication

Not applicable.

\section{Competing interests}

The authors declare that they have no competing interests.

\section{Author details}

'Social Development \& Health Promotion Research Center, Health Institute, Kermanshah University of Medical Sciences, Kermanshah, Iran. ${ }^{2}$ Department of Sport Management, Faculty of Sport Science, Razi University, Kermanshah, Iran.

Received: 15 March 2020 Accepted: 17 January 2021

Published online: 28 January 2021

References

1. Salvador-Carulla $L$, et al. Use of the terms" wellbeing" and" quality of life" in health sciences: a conceptual framework. Eur J Psychiatry. 2014;28(1):50-65.

2. Amati $V$, et al. Social relations and life satisfaction: the role of friends. Genus. 2018;74(1):7.

3. Helliwell JF. How's life? Combining individual and national variables to explain subjective well-being. Econ Model. 2003;20(2):331-60.

4. Diener E, et al. The satisfaction with life scale. J Pers Assess. 1985;49(1):71-5.

5. Ghasemi R, et al. The relationship of social support and self-efficacy with mental health and life satisfaction. J Mazandaran Univ Med Sci. 2017; 27(147):228-39.

6. Antaramian S. The importance of very high life satisfaction for students' academic success. Cogent Educ. 2017:4(1):1307622.

7. Banjare P, Dwivedi R, Pradhan J. Factors associated with the life satisfaction amongst the rural elderly in Odisha, India. Health Qual Life Outcomes. 2015; 13(1):201.

8. Hodacova $\mathrm{L}$, et al. Trends in life satisfaction and self-rated health in Czech school-aged children: HBSC study. Cent Eur J Public Health. 2017; 25(Supplement 1):S51-6

9. Lombardo $\mathrm{P}$, et al. The fundamental association between mental health and life satisfaction: results from successive waves of a Canadian national survey. BMC Public Health. 2018;18(1):342.

10. Ng ST, Tey NP, Asadullah MN. What matters for life satisfaction among the oldest-old? Evidence from China. PLoS One. 2017;12(2):e0171799.

11. Kelishadi $R$, et al. Self-Rated health and life satisfaction in Iranian children and adolescents at the national and provincial level: the CASPIAN-IV study. Iran Red Crescent Med J. 2016;18(12):e28096.

12. Sadeghpour A, Sadeghpour M, Hosseini M. The relationship of physical activity levels and mental health: a case study at Isfahan University of Medical Sciences, Iran. J Isfahan Med Sch. 2014;32(274):90-101.

13. Novak D, Doubova SV, Kawachi I. Social capital and physical activity among Croatian high school students. Public Health. 2016;135:48-55.

14. Daskalopoulou C, et al. Physical activity and healthy ageing: a systematic review and meta-analysis of longitudinal cohort studies. Ageing Res Rev. 2017;38:6-17.

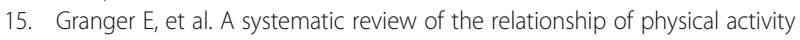
and health status in adolescents. Eur J Public Health. 2017;27(suppl_2):1006.

16. Baştuğ G, Duman S. Examining life satisfaction level depending on physical activity in Turkish and German societies. Procedia Soc Behav Sci. 2010;2(2): 4892-5

17. Saeed Niknafs E. Physical activity, life satisfaction and their role in job stress of military staff. Iran Occup Health. 2015;12(4):21-30.

18. Maher JP, et al. Daily physical activity and life satisfaction across adulthood. Dev Psychol. 2015;51(10):1407. 
19. Zusková K, Petričková L, Ortenburger D. Intensity of physical activity and life satisfaction of physical education teachers. TREND Sport Sci. 2019;2(26):91-7.

20. Valois RF, et al. Physical activity behaviors and perceived life satisfaction among public high school adolescents. J Sch Health. 2004;74(2):59-65.

21. Keyes CL, Shapiro AD. Social well-being in the United States: a descriptive epidemiology. How Healthy are we. 2004;15(3):350-72

22. Kassani A, et al. Determinants of social capital in Tehran residents using path analysis: urban HEART study. Iran J Epidemiol. 2012;8(2):1-12.

23. Field J. Social Capital. Tehran: Social Security Organization Research Institute; 2006.

24. Zou T, Su Y, Wang Y. Examining relationships between social capital, emotion experience and life satisfaction for sustainable community. Sustainability. 2018;10(8):2651.

25. Hoogerbrugge MM, Burger MJ. Neighborhood-based social capital and life satisfaction: the case of Rotterdam, the Netherlands. Urban Geogr. 2018; 39(10):1484-509.

26. Asadullah MN. Who trusts others? Community and individual determinants of social capital in a low-income country. Camb J Econ. 2017;41(2):515-44.

27. Cheung C-K, Kam PK. Bonding and bridging social capital development by social workers. J Soc Serv Res. 2010;36(5):402-13.

28. Rafiey H, Alipour F, LeBeau R, Salimi Y, Ahmadi S. Exploring the buffering role of social capital in the development of posttraumatic stress symptoms among Iranian earthquake survivors. Psychol Trauma Theory Res Pract Policy. 2019; https://doi.org/10.1037/tra0000524.

29. Winkleby MA, et al. Socioeconomic status and health: how education, income, and occupation contribute to risk factors for cardiovascular disease. Am J Public Health. 1992;82(6):816-20.

30. Calixto O-J, Anaya J-M. Socioeconomic status. The relationship with health and autoimmune diseases. Autoimmun Rev. 2014;13(6):641-54.

31. Huang S, et al. The effects of objective and subjective socioeconomic status on subjective well-being among rural-to-urban migrants in China: the moderating role of subjective social mobility. Front Psychol. 2017:8:819.

32. Fassbender I, Leyendecker B. Socio-economic status and psychological wellbeing in a sample of Turkish immigrant mothers in Germany. Front Psychol. 2018;9:1586

33. Mirmoghtadaee $P$, et al. The association of socioeconomic status of family and living region with self-rated health and life satisfaction in children and adolescents: the CASPIAN-IV study. Med J Islam Repub Iran. 2016:30:423.

34. Daraei M, Mohajery A. The impact of socioeconomic status on life satisfaction. Soc Indic Res. 2013;112(1):69-81.

35. Ueshima K, et al. Does social capital promote physical activity? A population based study in Japan. PLoS One. 2010;5(8):e12135.

36. Operario D, Adler NE, Williams DR. Subjective social status: reliability and predictive utility for global health. Psychol Health. 2004;19(2):237-46.

37. Odéen $\mathrm{M}$, et al. Expectancies, socioeconomic status, and self-rated health: use of the simplified TOMCATS questionnaire. Int J Behav Med. 2013;20(2): 242-51.

38. Vahedi S, Eskandari F. The validation and multi-group confirmatory factor analysis of the Satisfaction with Life Scale in nurse and midwife undergraduate students. Iranin J Nurs Res. 2010;5(17):67-79.

39. Cislaghi B, Cislaghi C. Self-rated health as a valid indicator for health-equity analyses: evidence from the Italian health interview survey. BMC Public Health. 2019;19(1):533.

40. Dobson AJ, Barnett AG. An introduction to generalized linear models. London: CRC Press; 2018.

41. Sun $\mathrm{S}$, et al. Subjective well-being and its association with subjective health status, age, sex, region, and socio-economic characteristics in a Chinese population study. J Happiness Stud. 2016;17(2):833-73.

42. Abbott P, Sapsford R. Life-satisfaction in post-soviet Russia and Ukraine. J Happiness Stud. 2006;7(2):251-87.

43. Asadullah MN, Chaudhury N. Subjective well-being and relative poverty in rural Bangladesh. J Econ Psychol. 2012;33(5):940-50.

44. Easterlin RA. Will raising the incomes of all increase the happiness of all? J Econ Behav Organ. 1995;27(1):35-47.

45. Haatainen $\mathrm{K}$, et al. Ftors associated with hopelessness: a population study. Int J Soc Psychiatry. 2004;50(2):142-52.

46. Hezarjaribi J And Feli J., Sense of Security and Its Relationship with Life Satisfaction (Case Study: PNU Students in Kermanshah Province). Soc Dev Welf Plann, 2016. 7(27): p. 117-144.

47. Ghasemi SR, et al. Social Capital and Happiness Among Health Sector Personnel in Iran. Iran J Psychiatry Behav Sci. 2017;11(4):e7912.
48. Woo M, Kim S. Does social capital always raise life satisfaction? A comparison of South Korea and Taiwan. Int J Soc Welf. 2018:27(2):121-31.

49. Mironova A. Trust as a factor of subjective life satisfaction. Higher School of Economics Research Paper No. WP BRP, vol. 42; 2015.

50. Kööts-Ausmees $L$, Realo A. The association between life satisfaction and selfreported health status in Europe. Eur J Personal. 2015;29(6):647-57.

51. Reyes Fernández B, Rosero-Bixby L, Koivumaa-Honkanen H. Effects of selfrated health and self-rated economic situation on depressed mood via life satisfaction among older adults in Costa Rica. J Aging Health. 2016;28(2): 225-43

52. Schneider $\mathrm{G}$, et al. What influences self-perception of health in the elderly? The role of objective health condition, subjective well-being and sense of coherence. Arch Gerontol Geriatr. 2004;39(3):227-37.

53. Jiménez MdMS, Caselles JA, Jiménez FJS. Education and satisfaction with life: the role of positional concerns. In: XVIII Encuentro de economía pública; 2011.

54. Martikainen L. Life satisfaction of university-educated young adults. In: The psychology of happiness: A good human life. Cambridge: Cambridge University Press; 2009

55. Aysan MF, Aysan U. The effect of employment status on life satisfaction in Europe. In: Empirical studies on economics of innovation, public economics and management. Switzerland: Springer; 2017.

56. Habibi N. Iran's overeducation crisis: causes and ramifications. Middle East Brief. 2015:85:1-7.

57. Botha F, Booysen F. The relationship between marital status and life satisfaction among south African adults. Acta Academica. 2013:45(2):150-78.

58. Han K-T, et al. Is marital status associated with quality of life? Health Qual Life Outcomes. 2014;12(1):109.

59. Waite LJ. Does marriage matter? Demography. 1995;32(4):483-507.

60. Stutzer A, Frey BS. Does marriage make people happy, or do happy people get married? J Socio-Econ. 2006;35(2):326-47.

\section{Publisher's Note}

Springer Nature remains neutral with regard to jurisdictional claims in published maps and institutional affiliations.
Ready to submit your research? Choose BMC and benefit from:

- fast, convenient online submission

- thorough peer review by experienced researchers in your field

- rapid publication on acceptance

- support for research data, including large and complex data types

- gold Open Access which fosters wider collaboration and increased citations

- maximum visibility for your research: over $100 \mathrm{M}$ website views per year

At $\mathrm{BMC}$, research is always in progress.

Learn more biomedcentral.com/submissions 